NBER WORKING PAPER SERIES

\title{
SEX DIFFERENCES IN OBESITY RATES IN POOR COUNTRIES: EVIDENCE FROM SOUTH AFRICA
}

\author{
Anne Case \\ Alicia Menendez \\ Working Paper 13541 \\ http://www.nber.org/papers/w13541
NATIONAL BUREAU OF ECONOMIC RESEARCH
1050 Massachusetts Avenue
Cambridge, MA 02138
October 2007

This research has been supported by grants from the National Institute on Aging (R01 AG20275-01, P01 AG05842-14, and P30 AG024361). We thank Dr. Ingrid le Roux and the Philani Nutrition Programme, without whose generous help and guidance this project would not have been possible. The views expressed herein are those of the author(s) and do not necessarily reflect the views of the National Bureau of Economic Research.

(C) 2007 by Anne Case and Alicia Menendez. All rights reserved. Short sections of text, not to exceed two paragraphs, may be quoted without explicit permission provided that full credit, including $\odot$ notice, is given to the source. 
Sex Differences in Obesity Rates in Poor Countries: Evidence from South Africa

Anne Case and Alicia Menendez

NBER Working Paper No. 13541

October 2007

JEL No. D13,I10

\begin{abstract}
$\underline{\text { ABSTRACT }}$
Globally, men and women face markedly different risks of obesity. In all but of handful of (primarily Western European) countries, obesity is more prevalent among women than men. In this paper, we examine several potential explanations for this phenomenon. We analyze differences between men and women in reports and effects of the proximate causes of obesity -- physical exertion and food intake -- and the underlying causes of obesity -- childhood and adult poverty, depression, and attitudes about obesity. We evaluate the evidence for each explanation using data collected in an African township outside of Cape Town. Three factors explain the greater obesity rates we find among women. Women who were nutritionally deprived as children are significantly more likely to be obese as adults, while men who were deprived as children face no greater risk. In addition, women of higher adult socioeconomic status are significantly more likely to be obese, which is not true for men. These two factors can fully explain the difference in obesity rates we find in our sample. Finally (and more speculatively), women's perceptions of an 'ideal' female body are larger than men's perceptions of the 'ideal' male body, and individuals with larger 'ideal' body images are significantly more likely to be obese.
\end{abstract}

\author{
Anne Case \\ 367 Wallace Hall \\ Princeton University \\ Princeton, NJ 08544-1022 \\ and NBER \\ accase@princeton.edu \\ Alicia Menendez \\ Harris School of Public Policy \\ University of Chicago \\ Chicago, IL 60637 \\ menendez@uchicago.edu
}




\section{Introduction}

People living in developing countries are burdened not only by the infectious diseases of the developing world, but increasingly by the chronic diseases of the developed world. The incidence of obesity is on the rise in many poor countries (Popkin and Doak 1998). Globally, men and women face different risks of obesity. Data from the World Health Organization (WHO) suggest that, in all but of handful of (primarily Western European) countries, obesity is more prevalent among women than men. In 138 of 194 countries for which the WHO reports obesity statistics, women were more than 50 percent more likely to be obese than were men (WHO Global InfoBase: obesity and overweight, available online at http://www.who.int/topics/obesity/en/). The prevalence of obesity among women in Southern Africa is particularly high (Martorell et al 2000). In South Africa, Puoane et al. (2002) find that 60 percent of African (Black) women in 1998 were either overweight or obese, with rates of obesity five times higher for Black women than for Black men. ${ }^{1}$

Chronic health risks associated with obesity include, inter alia, hypertension, coronary heart disease, stroke and diabetes. Recent work concludes that overweight Africans are not immune to these risks. In one rural demographic surveillance site in South Africa, where nearly 50 percent of women are overweight or obese, women with higher body mass indices (BMI) were found to be at higher risk of hypertension (Case and Deaton 2006). The two largest killers in that field site, among residents aged 50 and

\footnotetext{
${ }^{1}$ We follow World Health Organization classifications that a person is overweight if his or her body mass index (BMI) - a measure of weight for height (kilograms per meter squared) - lies between 25 and 30, and is obese if his or her BMI is greater than 30. For example, a person 5 foot 4 inches tall would be classified as overweight if her weight were above 145 pounds, and obese if her weight were greater than 175 pounds.
} 
above, are stroke and congestive heart failure - both diseases associated with obesity (Kahn et al. 1999).

Recent literature points to several risk factors for obesity in developing countries. The focus of this work is generally on factors that shift the calorie intake-expenditure balance, including increased urbanization, which can lead to a reduction in physical activity; the availability of lower priced calories, which can lead to greater calorie consumption; and a "Westernization" of diets (Popkin 1994, WHO 2000). FAO (2006) cites the importation of high-fat foods into low income countries as a central underlying cause of the pandemic.

All of these factors may contribute to the increased prevalence in obesity in the developing world. However, by themselves these factors cannot explain why the rates of obesity are significantly higher for women than for men in developing countries. In this paper, we examine several potential explanations for the much higher obesity rate observed for African women in South Africa. Specifically, we analyze differences between men and women in reports and effects of the proximate causes of obesityphysical exertion and food intake — and underlying causes of obesity — childhood and adult poverty, depression, and attitudes about obesity. We evaluate the evidence for each explanation using data collected in 2004 and 2005 on the health, mental health and socioeconomic circumstances of individuals living in Khayelitsha, an African township outside of Cape Town, South Africa.

Three factors explain the greater obesity rates we find among women. Women who were nutritionally deprived as children are significantly more likely to be obese as adults, while men who were deprived as children face no significantly greater risk of obesity. In 
addition, women of higher adult socioeconomic status (SES) are significantly more likely to be obese, which is not true for men. These two factors can fully explain the difference in obesity rates between men and women in our sample. Finally (and more speculatively), women's perceptions of an 'ideal' female body are larger than men's perceptions of the 'ideal' male body, and individuals with higher 'ideal' body images are significantly more likely to be obese. On average, South African Black women report that their body size accords with their 'ideal' at a body mass index (BMI) of 30 - the lower bound of the World Health Organization's definition of obesity.

In what follows, we examine sex differences in obesity rates in South Africa. The next section presents a model of the proximate and underlying causes of obesity. In addition, it presents a decomposition of obesity into component parts, which we use to discuss differences in obesity rates between men and women. Section 3 provides an introduction to our data, and Section 4 presents results on the determinants of obesity in South African women and men. Section 5 discusses mechanisms through which childhood and adult SES appear to differentially affect women's and men's obesity, and Section 6 highlights implications of these findings for health interventions and suggests avenues for future research.

\section{Proximate and Underlying Causes of Obesity}

Proximate causes of obesity

Obesity results from an imbalance between calorie intake and expenditure. Adults surveyed in Khayelitsha were asked many questions about food and drink, and about physical activities. These behaviors $\left(x_{b}\right)$ are the observable components of energy intake 
and expenditure that we use to characterize the proximate causes of obesity. We write the probability that an individual is obese $(y=1)$ as a function of the observable proximate causes:

(1) $\quad P(y=1)=x_{b} \gamma_{b}+u$.

The survey does not capture all calorie intake and expenditure. There are many questions (for example, about the amount of oil that goes into the cooking pot, and more generally the fat content of foods consumed) that are difficult to ask with any precision. The error component of (1), then, will contain several measures of energy intake and expenditure that influence obesity. We can re-write the error term to reflect this,

$u=x_{b^{*}} \gamma_{b^{*}}+e$,

where $x_{b^{*}}$ represent those elements of calorie intake and expenditure that are not captured by the survey. We can then re-write equation (1) to reflect also the latent determinants of obesity:

$$
P(y=1)=x_{b} \gamma_{b}+x_{b^{*}} \gamma_{b^{*}}+e .
$$

\section{Underlying causes of obesity}

Obesity may depend on factors individuals encounter at different points in the life course. Childhood deprivation may change the probability of obesity in adulthood directly, 
through its effects on metabolic function. In addition, childhood poverty may determine educational attainment and financial status in adulthood, which may affect consumption patterns. Adults' attitudes, and their dispositions toward depression, can also affect their calorie balance. We refer to these collectively as the underlying factors affecting the probability of obesity.

We formalize this by representing the observable and latent components of energy intake and expenditure as a function of vectors of childhood circumstances $\left(x_{c}\right)$, adult socioeconomic status $\left(x_{s}\right)$, and adult attitudes, predispositions toward depression, and perceptions of the ideal body $\left(x_{d}\right)$. That is

$x_{b}=x_{c} \alpha_{c}+x_{s} \alpha_{s}+x_{d} \alpha_{d}+v$
$x_{b^{*}}=x_{c} \alpha_{c^{*}}+x_{s} \alpha_{s^{*}}+x_{d} \alpha_{d^{*}}+\omega$

Substitution of these underlying characteristics into (2) allows us to express the association between obesity and its underlying causes as

(3) $\mathrm{P}(y=1)=x_{c} \beta_{c}+x_{s} \beta_{s}+x_{d} \beta_{d}+\varepsilon$.

The coefficients on childhood and adult circumstances reflect both the observable and latent determinants of obesity. The coefficients on childhood variables, for example, measure the extent to which childhood circumstances affect relevant observable and latent behaviors, interacted with the extent to which these behaviors change the probability of obesity: $\beta_{c}=\alpha_{c} \gamma_{b}+\alpha_{c^{*}} \gamma_{b^{*}}$. 
We can estimate equations (1) and (3) to quantify the proximate and underlying causes of obesity. We can also use these equations to characterize the reasons for women's much greater rates of obesity. We quantify differences between men and women in their endowments of variables that determine obesity, and differences in the impact of these variables, by decomposing equations (1) and (3) using a Blinder-Oaxaca decomposition. Re-writing equation (3) for women $(F)$ and men $(M)$ as

$\mathrm{P}^{k}(y=1)=\sum_{i} x_{i} \beta_{i}^{k}+e^{k}$ for $k=F, M$

the difference in obesity rates between women and men can be expressed as a severity effect, which measures the differences between sexes in the extent to which individual characteristics affect obesity; and a prevalence effect, which measures differences in endowments of characteristics thought to influence obesity; and a residual, which picks up any remaining differences in rates between men and women. The severity effect can be written

(4) severity effect $=\sum_{i}\left(\beta_{i}^{F}-\beta_{i}^{M}\right) \overline{x_{i}}$

where $\bar{x}_{i}$ is the mean of characteristic $i$ over the sample. The prevalence effect can be written

(5) prevalence effect $=\sum_{i}\left(\overline{x_{i}^{F}}-\overline{x_{i}^{M}}\right) \overline{\beta_{i}}$ 
where $\overline{x_{i}^{k}}$ measures the mean of characteristic $i$ for sex $k$ in the sample, and $\overline{\beta_{i}}$ is the mean of the response to characteristic $i$ averaged between that estimated for women and that estimated for men. To the extent that one sex is more heavily endowed with a characteristic that affects obesity, this will contribute to the prevalence effect. We estimate the severity and prevalence effects for both the proximate and underlying causes of obesity, and present them in Section 4.

There are many reasons why childhood circumstance, adult SES, and adult attitudes could lead to differences in obesity rates between men and women.

\section{Childhood circumstance}

In animal studies, males and females have been shown to respond differently to early postnatal exposure to hypothalamic neuropeptides known to affect the appetite regulation system. Varma et al. (2003), for example, find significant sex differences in early life exposure to neuropeptide $\mathrm{Y}$ on adult weight control in rats. They suggest that differences between males and females may be due to differential effects of sex steroids on neuropeptide synthesis and/or release. Early life conditions may have permanent effects on appetite regulation, feeding behaviors, and body weight gain patterns. In our data, we can examine whether and to what extent men and women raised in poor households, specifically those who report having gone hungry as children, face different risks of obesity, which would be consistent with a differential impact of early life nutritional deprivation on appetite and weight regulation in adulthood. 


\section{Adult socioeconomic status}

An extensive literature has documented the extent to which resource allocation can vary by sex within households, in both developed and developing countries (see Bergstrom 1997 for a review). In many studies, women have been found to have a greater say in household decisions when their incomes constitute a higher fraction of total household income. When resources are scarce, women may choose not to eat, to guarantee that there is enough food for children. Indeed, lack of household resources in South Africa has been shown to be significantly correlated with adults missing meals there (Case 2004). In addition, when resources are scarce, women may have less say in how money in the household is spent. Making decisions on who should eat, and having the power to make decisions on food spending, may result in differences in male-female obesity rates at different levels of household SES. In our data, we can examine whether and to what extent current household economic status is associated with differential obesity in men and women, and whether differences in obesity rates by SES can be explained by differences in women's decision-making power in the household.

\section{Depression}

On average, South African women report suffering from a greater number of symptoms

of depression than do South African men (Case and Deaton 2006). Studies in the US have generally found a positive association between obesity and depression in women, and either a negative association, or no association, between obesity and depression in men (See Onyike et al. 2003, and references there.) Depression may change eating patterns, and may lead to differential weight gain between men and women. In our data, we can 
examine both the extent to which men and women differ in their reports of depression, and the extent to which depression correlates differentially with obesity between men and women.

\section{Perceptions of body sizes}

Women and men's opinions on the relative attractiveness of different body shapes could potentially affect the sizes to which they aspire. Across cultures, significant differences have been found in evaluations of body images. Holdsworth et al. (2004) show that, among Senegalese women, overweight figures are regarded as attractive and are associated with positive personal characteristics. Furnham and Baguma (1994) find significant differences in what is considered beautiful and healthy, in a comparison between Ugandan and British college students. Ugandans rate more obese bodies as more attractive and healthier than British student do, particularly in the case of female figures. In our data, we can examine the extent to which differences in obesity rates are associated with differences in male and female perceptions of what constitutes an 'ideal' male and female body.

In the following section, we introduce the data we collected in South Africa to examine the difference we observe in obesity rates between men and women.

\section{Data}

In 2004 and 2005, we collected data on 500 randomly selected households in Khayelitsha, an African township with a population in excess of 500,000 people. The township contains both houses with access to water and electricity, and shacks with 
access to neither. Most households have a family connection to the Eastern Cape, one of the poorest parts of South Africa (Leibbrandt et al. 2005), from which family members originally migrated. Poverty rates in the township are high, and the community faces major health problems in HIV and AIDS, TB, violence and malnutrition.

We surveyed every adult living in our sampled households individually, asking each about his or her family background, income and earnings, general health and mental health, and health related behaviors. All adults were weighed and measured. ${ }^{2}$

Table 1 presents summary statistics for 975 individuals, out of the 1001 adults in our 2004 and 2005 samples, for whom we have a BMI reading. ${ }^{3}$ Our focus is largely on the differences in obesity prevalence between the sexes, and for this reason we present the $p$-value of the statistical significance of the difference in sample means between men and women in column 3 .

Three-quarters of the women in our sample are either overweight or obese, true of only thirty percent of men surveyed. The patterns observed between and within sexes are similar to those found among urban Africans (Blacks) in the 1998 South African Demographic and Health Survey. (Results available upon request.)

The BMI-age profiles underlying these statistics are presented in Figure 1. Similar to the patterns found in other parts of South Africa, we find BMI increasing with age until age 40. Thereafter, BMI is approximately constant with age. For women,

\footnotetext{
${ }^{2}$ These households were originally interviewed in 2002 and 2003. In the 2004 and 2005 follow-up, we succeeded in reinterviewing 427 original households, and 9 households where members had split from our original sample.

${ }^{3}$ Sex is missing for one observation. Of the remaining 25 missing values, height measurements were missing for 7 persons too ill to stand; 7 who did not want to be measured; and 6 persons for whom no reason for refusal was given. In addition, weight measurements were missing for one person too large for our scales (350 pounds), and 4 pregnant women.
} 
stabilization in BMI occurs at a BMI well in excess of 30. For men, it occurs at a BMI just shy of 25, the WHO lower bound for 'overweight.' From this cross-section, we cannot know whether these patterns represent age or cohort effects. The cross-section cannot tell us whether today's 20 year old women, at age 35 , will continue to have average BMIs of 25 (as they do at age 20), or whether their BMIs will more closely resemble those of today's 35 year olds.

In addition to the age pattern, the other obvious pattern observable in Figure 1 is that, at every age, women's BMIs are 5 to 8 points higher than men's. Even the youngest women in our sample are overweight on average, registering BMIs in excess of 25.

Table 1 also presents summary statistics on variables we will use to examine determinants of obesity and male-female differences in prevalence rates.

\section{Proximate causes}

We asked all individuals about their eating habits, and had them report on the sizes of their meals. A significantly greater proportion of men than women report eating large meals, based on their identification of the most accurate portion sizes among pictures they were shown. Men are also more likely to report drinking soda, while women report using more sugar in tea and coffee over the course of a day. There are large outliers in reported sugar use. For this reason, in our analysis we will use a sugar index, equal to 0 if no sugar is reported, equal to 1 if 1 to 9 spoonfuls per day are reported, equal to 2 if 10 to 19 spoonfuls are reported, and so on up to a measure of 5, if 40 or more spoonfuls per day are reported. 
Men are significantly more likely to report that they exercise and participate in sports, although neither men nor women report much by way of physical activity. We will examine below the extent to which these differences can explain women's greater obesity rates. ${ }^{4}$

\section{Underlying causes: childhood circumstances}

We did not observe these adults as children, and so it is not possible to measure with any precision the nutritional risks they faced in early life. However, subjects had little difficulty telling us whether, as children, there were times when they went to school hungry, went to bed hungry, or ate at other people's homes because there was not enough food at home. More than a third of men and women report having gone to school and to bed hungry, and just over a quarter report having gone to other homes to eat. Differences between men and women in these reports are small, and are not statistically significant.

In our analysis, we will use a 'childhood hunger index,' which we define as the sum of reports that a respondent went to school hungry, went to bed hungry, and ate at other people's houses because there was not enough food at home. Almost 60 percent of our sample report none of these events in childhood. Of the rest, approximately 10 percent report one of the three, 10 percent report two of the three, and 20 percent report all three. The overall means for men (1.02) and women (0.98) are very similar.

\section{Adult SES}

\footnotetext{
${ }^{4}$ We asked all adults about alcohol consumption. However, rates reported were very low, and we believe respondents may have been reluctant to talk about alcohol use. We will treat alcohol consumption as a latent proximate determinant of obesity.
} 
Both men and women have completed more than 6 years of schooling, with women reporting an extra half year, on average, relative to men. Educational attainment provides one of our measures of adult SES. An individual's current financial situation, measured using income per person and household-level expenditures per person, provides the other. A 'knowledgeable household member' (KHM) was asked about earnings, social transfers from the government (primarily pensions and grants), and private transfers coming into the household in a typical month, from which we generate a measure of income per person. In addition the KHM was asked about household-level expenditures in a normal month, including spending on food, rent, utilities, fuel, household phones, and furniture, from which we generate a measure of household-level expenditure per person.

Income per person is substantially higher than expenditure per person, because we have not included personal spending (clothing, personal cell phones, transportation, for example) in our measure of household spending. On average, men are residing in slightly wealthier households, with household-level expenditures per person 10 percent higher, and income per person 20 percent higher, than those found for women.

These two measures of resources available in the household were constructed in different ways, with expenditures aggregated up from spending on such items as meat, bread, electricity and paraffin, and incomes aggregated up from reported receipts of child support grants, old age pensions, and earnings, for example. We are interested in whether the SES-obesity patterns we observe are robust to the measure of SES that we choose.

\section{Depression}


We are also interested in whether stress and depression play a role in obesity. We asked each person whether he or she had experienced any of 8 symptoms of depression in the last week and, if so, whether each occurred 'most of the time," "some of the time," or "hardly ever." We asked about depression, sadness, crying, poor appetite, trouble sleeping, everything being an effort, feeling miserable, and not feeling able to 'get going.' From the answers received, we created a depression index, which is the sum of the number of times a person reported he or she had felt this symptom 'some of the time,' or 'most of the time.' Women report significantly more depression symptoms than do men in our sample. On average, women report that they had experienced three of these symptoms 'some' or 'most of the time' in the past week, while men report two symptoms.

\section{Body images}

Every person interviewed was asked their perceptions about body images. Following an introduction that "Sometimes we have ideas about how we look, and how we might like to look," the respondents were shown pictures of eight people of their sex, whose images varied from being bone thin (rated as a 1) to being morbidly obese (rated as an 8). These figures were originally used by Ziebland et al. (2002), who gave us permission to use them in our survey work. We reproduce them here, in Figure 2. Each respondent was asked which best described their body size, and which best described the shape they would most like to have. Women on average perceive themselves to have a body size of '4,' and on average see a '4' as the 'ideal' body. Men see themselves as somewhat lighter, and on average would like to be a bit heavier. 
In summary, women and men report significant differences in their food consumption patterns, reports of sports and exercise, depression symptoms, and ideas of an 'ideal' body shape. Women have slightly more education, but are living in households that are marginally poorer, on average. We turn in the next section to evaluate the extent to which these proximate and underlying causes can explain the patterns of obesity we find in South Africa.

\section{Determinants of obesity in South Africa}

Table 2 presents estimates of the proximate causes of obesity from OLS regressions run separately for men and women. All regressions include controls for age, age squared, an indicator for the survey year, and a constant term. Standard errors, which allow for correlation in the unobservables for individuals from the same households, are presented in parentheses under the regression coefficients. (Marginal effects from probit regressions are very similar. We focus on the OLS results because they allow an exact linear decomposition of sex differences into component parts.)

For women, meal sizes, drinking soda, and the sugar added to tea and coffee are all significantly associated with obesity. Our sugar index is in increments of 10

spoonfuls, so that a woman who adds 15 teaspoons of sugar to her tea over the course of a day is 10 percentage points more likely to be obese ( 2 times 0.05 ) than a woman who reports adding no sugar. For men, neither large meal sizes nor reported sugar intake is associated with obesity, while drinking soda is marginally significantly associated with obesity. Reporting exercise or sports is not associated with lower probability of obesity for either men or women. 
Overall, women's reported food intake is significantly associated with obesity (an $F$-test of the joint significance of the food intake variables takes a value of 4.27, with a $p$ value of 0.006 ). Women's observable energy expenditure variables are not significantly associated with obesity. For men, neither reported calorie intake nor calorie expenditure is significantly associated with obesity.

We can use the results in Table 2 to examine whether observable calorie intake and expenditure can explain differences in obesity rates between women and men, by decomposing the proximate causes of obesity into severity and prevalence effects. These are presented in Table 3. Sugar intake can explain 6.0 percentage points of the difference between obesity rates between men and women; large meals, 2.1 percentage points; and soda, 1.1 percentage points. We find that, collectively, the observable proximate causes can explain about 20 percent of the difference in obesity rates between men and women $(0.085 / 0.402)$. All of this explained difference is due to differences in the impact of reported food intake on obesity in women (the severity effect). Men are more likely to report sports and exercise. However, because these are not associated with obesity (or lack of obesity) for men or women, the prevalence effects are very small.

Too few observable energy intake and expenditure variables are available to estimate the impact of different proximate causes with any precision. We turn to the underlying causes of obesity, which indirectly pick up the effects of both observable and latent energy variables.

Table 4 presents evidence from a variety of specifications of the underlying causes of obesity. For women and men separately, the first column regresses obesity on our childhood hunger index, and on the log of income per household member, as well as 
education, and our depression index. The second column interacts log(income per member) with the childhood deprivation measure, to test whether respondents who were poor in childhood are at greater risk for obesity if they have greater access to resources in adulthood. The third column replicates the second, but uses $\log$ (expenditure per member) in place of income, to test the robustness of our findings.

For women, childhood deprivation, measured using our childhood hunger index, is positively and significantly associated with obesity. Women who reported going to bed hungry, and to school hungry, and who ate at others' houses because there wasn't enough food, are 15 percentage points more likely to be obese than are women who report none of these. This result holds with or without controls for current socioeconomic status.

Higher socioeconomic status in adulthood, measured using years of education, is positively and significantly related to obesity in women. In addition, women in households with greater resources, measured using the log of income per member, are significantly more likely to be obese. Moving a woman from the $25^{\text {th }}$ percentile to the $75^{\text {th }}$ percentile of the distribution of income per person (measured at either the individual or the household level) is associated with an increase in obesity among women of 10 percentage points.

We examine the extent to which current household resources have differential effects on women, depending on whether they were poor as children, by adding a child povertyhousehold income interaction term in column 2. Neither the childhood deprivation measure nor the interaction term is significant by itself. However, jointly they are significant $(F$-test $=4.67, p$-value $=0.010)$. This is consistent with a model in which greater deprivation in childhood has larger effects in adulthood among those who are wealthier in 
adulthood. We find a similar pattern when we use $\log ($ expenditure per member) in place of $\log ($ income per member), in column 3 .

Depression is not significantly associated with obesity in women. This continues to be true when the 8 component pieces of the index are entered separately, and when we divide responses into those reporting depression symptoms 'some' of the time, and those reporting them 'most' of the time. (These results were estimated, but are not reported in our tables).

The association between obesity and individual and household characteristics is altogether different for men. While men are equally likely to report having been raised in poor households, such reports by men are not associated with higher rates of obesity (column 4). In addition, current SES, measured using log(income per member) or $\log ($ expenditure per member), has no significant association with obesity in men. Male obesity is also orthogonal to reports of depression. We find a small, marginally significant effect of education on obesity in men.

We decompose the differences between women and men into severity and prevalence effects in Table 5. As was true of proximate causes of obesity, the decomposition underscores the fact that differences in obesity are not due to differences in endowments of the economic variables examined here- the prevalence effect is very close to zero $(-0.001)$. Obesity differences between the sexes appear, instead, to be due to the differences that socioeconomic status has on the probability of obesity. Aggregating the effect of childhood hunger and its interaction effect with income, we find that childhood hunger accounts for 13 percent of the difference in obesity rates between women and men $(0.053 / 0.402)$. The impact of education accounts for 16 percent of the difference 
(0.063/0.402). Two-thirds of the difference between men and women is due to the difference in the impact of current household resources on obesity.

Differences in the impact of current and past economic circumstances explain 100 percent of the difference in obesity rates by sex in our sample. We turn next to examine what these differences in the impact of SES may reflect.

\section{Understanding the effects of SES on obesity}

\section{Childhood deprivation}

Our childhood hunger index measures the extent to which respondents went hungry in childhood. We can distinguish whether its effects on women's obesity in adulthood appear to be due to nutritional deprivation, or to poverty more broadly, by examining several other measures of childhood deprivation that we collected on each respondent. We asked each whether his or her financial situation in childhood was "very comfortable, comfortable, just getting by, poor or very poor.” Fifty percent of respondents answered that their households were "just getting by," and 37 percent that they were "poor" or "very poor." In addition, we asked respondents whether their fathers had stable employment (a "regular pay job") when they were children (true for approximately twothirds of respondents).

Table 6 presents results of our childhood hunger index regressed against indicators of financial status in childhood and of whether the respondent's father had a regular pay job. Our hunger index is highly correlated with these measures of childhood economic status, as can be seen in the first two columns of the table. For both men and women, father not having had a regular pay job is associated with an increase of 0.2 in 
our childhood hunger index. The associations between the childhood hunger index and reports on childhood financial status are very similar between men and women. Adults who report that their families' financial situations were either "very comfortable" or "comfortable" have a hunger index that is, on average, 2.2 points lower than those who report that their families were "very poor," the reference group for this regression. Those whose families were "just getting by" report a hunger index that is 1.7 to 1.8 points lower, and those whose families were "poor" report a hunger index that is 0.5 to 0.6 points lower than those whose families were "very poor." The difference between reporting that their families were "comfortable" and reporting that they were "just getting by" is significant, as is the difference between reporting "just getting by" and being "poor." Jointly, the reports of childhood financial wellbeing are highly significant for both women $(F$-test $=101.3, p$-value $=0.000)$ and $\operatorname{men}(F$-test $=60.3, p$-value $=0.000)$.

We test whether it is nutritional deprivation, or economic deprivation in childhood more broadly, that is associated with obesity in adult women, by adding all three measures of childhood SES to our obesity equations. Results from these regressions are presented in the last two columns of Table 6 . We find that the inclusion of indicators of family financial status in childhood, and of whether the respondents' fathers held regular pay jobs, are not significantly associated with obesity for either women or men. The only measure of childhood circumstance that is significantly associated with obesity in adulthood is our indicator of hunger in childhood for women. With or without the additional controls for childhood SES, we find that each unit increase in our childhood hunger index is associated with a five percentage point increase in the probability that a woman is obese. 
Future work is warranted to see what aspects of childhood nutritional deprivation are responsible for adult obesity in women. Such work must combine biology and social science, if we are to understand why this effect in childhood affects only women. Such work may also help us better understand the seemingly ironic finding that poor countries struggling with malnutrition must also cope with obesity.

\section{Adult SES}

We find that, for women, obesity is associated with higher adult SES. The same is not true for men. In this section, we examine potential explanations for this difference. We present our findings in two parts. We find that women's own incomes fully explain the association between total household income and women's obesity. Part of the association between women's incomes and their obesity appears to work through wealthier women's decision-making role in food spending: women with higher incomes appear to have greater control over household food spending. After presenting these results, we ask why women's control over resources would lead them to be obese, while men's control over resources does not. Given that women and men have different perceptions of 'ideal' body shapes, we examine whether they use the resources under their command to move toward different ideals.

Women's incomes, household decision-making, and obesity

Control over resources may be one of the mechanisms contributing to the relationship between adult SES and women's obesity. We examine this in Table 7, where we regress the probability of being obese on different components of household income, with and 
without controls for who has the most say in food spending. In order to analyze different parts of household income, we present results for income in levels, rather than in logs, so that we do not lose observations for respondents who did not earn money.

Consistent with the results presented in Table 4, we find that women residing in households with greater total household income are significantly more likely to be obese. Men face no increased risk of obesity with household income (column 4).

Decomposing total household income into component parts (column 2) makes it clear that the association between household income and a woman's obesity is driven by women's own income. The two large sources of income for women in our survey are women's own earnings, and their receipt of child support grants. Fully a third of all women earn income from working, and a third receives a child support grant from the government. ${ }^{5}$ When we add women's income from these sources, both women's earnings and their child grant receipt are positively and significantly correlated with obesity, while the estimated effect of total household income becomes smaller and insignificantly different from zero. On average, each additional R1000 per month in earnings is associated with a 6.2 percentage point increase in obesity for women, holding all else constant. Women receiving R170 in the form of a government child support grant are 5.7 percentage points more likely to be obese than are women not receiving a grant $(0.337 \times$ 0.170). For men we find no effect of either total household income (column 4), or own earnings (column 5), on obesity.

\footnotetext{
${ }^{5}$ In contrast, only 5 percent of women report receipt of an old age pension (most are not age eligible). Another 5 percent report a disability grant. With respect to child support grants, at the time of our survey, children from ages 0 to 7 were eligible to receive between R160 to R180 per month through a primary care giver, who is generally (but not restricted to be) the child's mother, if the primary care giver's monthly income was less than R1100 and he or she was living in an informal house or shack. Men are only rarely reported to be child grant recipients. In our data, 3 men were so named.
} 
Total household income is not significantly correlated with women's obesity in regressions that include both total household income and women's own incomes, while women's incomes are significantly correlated with obesity. This suggests that a woman's own income, and income coming into her household from other sources, have different effects on her calorie intake and expenditure, on average.

Part of this difference appears to work through the fact that women are significantly more likely to control household food spending when their own incomes are higher. In the household module of our Khayelitsha survey, we asked the knowledgeable household member which members of the household "had the most say in decisions about spending on food." Table 8 presents regression results for being identified as such a decision-maker, for all adults living in households that contain both adult men and women as members. We present regression results for having 'the most say' on food spending regressed on total household income and its interaction with being female, earnings from work and its interaction with being female, and child grant receipt (here only interacted with being female, since men only rarely receive child support grants). In this regression, we control for the member's education, age, and age squared, which may affect a member's decision-making powers within the household, and for the number of household members, which may reduce the odds that any given person is named as the decision-maker.

We find that women's incomes make them significantly more likely to be reported as the decision-maker for household food spending. Controlling for women's own incomes, the effect of total household income is small and insignificantly different 
from zero. A woman's own income appears to increase her voice in household food spending decisions.

In turn, being the decision-maker for household food spending is significantly associated with obesity in women. On average, women who have the most say in household food spending are 10 percentage points more likely to be obese. (See column 3 of Table 7.) Inclusion of an indicator that the respondent has been identified as having the most say on food spending reduces the estimated effects of own-earnings and child grant receipt on women's obesity by more than 20 percent. As was true of our earlier results, we find no effects of total household income, or own-earnings, or having the most say on food spending, on men's obesity.

Most of the effect of women's incomes on obesity works through latent calorie intake and expenditure variables. There is no significant association between women's own-earnings and reported meal sizes, or reported exercise or sports. Women who receive child support grants report significantly higher sugar intake. Those who report higher earnings are more likely to report that they drink soda. Taken overall, there must be many unobserved energy variables that vary with women's incomes.

Why are women with higher incomes more likely to be obese? One possibility is that women admire larger body sizes. When we ask women about their body size, we find that women with larger BMIs are significantly more likely to report that they are larger, measured using the body size pictures. On average, each one-unit increase in BMI is associated with women stating that their own body size is 0.12 pictures larger. Figure 3 presents evidence that, on average in our survey, a woman's perceived body size equals her ideal body size at a BMI just below 30 - which is the WHO lower bound for obesity. 
Women with BMIs below thirty, on average, report that their 'ideal' is larger than their actual body size, while women with BMIs above thirty believe their ideal is below their actual size. On average, women's ideal size is equal to her self-perceived body size at a BMI of 29.45. In contrast, for men, ideal size is equal to self-perceived body size at a BMI of 24.23. If women are targeting a BMI of 30, while men are targeting a BMI of 25 , this could lead to women with money using it, in part, to move their BMIs toward 30.

\section{Conclusions}

Using data from an African township in South Africa, we are able to identify the underlying causes of differences between men's and women's obesity. We find that poverty in childhood, and greater access to resources in adulthood, lead women to be at significantly greater risk of obesity than are men. In adulthood, there is a significant and substantial difference in the body sizes to which men and women aspire. Women with more control over their resources may use these resources to reach and maintain larger body sizes.

Economic research has highlighted the positive child outcomes associated with putting money into women's hands. (See, for example, Hoddinott and Haddad 1995.) However, this may come at a cost, if it increases the probability that women become obese.

Understanding the differences that men and women face in their risks of obesity is a necessary and important first step for effective policy intervention. If women aspire to large body sizes, then we would not expect a campaign to spread general information on the calorie, fat and nutrition content of food would take us very far in reducing the 
obesity risk that women face. One way to address women's high prevalence rates may be to better educate women on the relevant risks that they face when their BMI becomes large. In that way, women's perceptions of an ideal body size may change.

There may be an upper bound on the extent to which such campaigns will be successful, however, if a woman's ability to regulate her appetite is compromised by the nutritional deprivation she endured as a child. Our results on the differences in obesity risk faced by men and women, who reported similar childhood nutritional deprivation, suggest that the biology of obesity risk cannot be fully understood without understanding early-life economic disadvantage, and that the impact of socioeconomic status on obesity cannot be understood without a biological framework that can explain why women and men, facing the same nutritional deprivation as children, face quite different biological risks as adults. 


\section{REFERENCES}

Bergstrom, T. C. 1997. "A survey of theories of the family," Chapter 2 in Handbook of Population and Family Economics, M. R. Rosenzweig and O. Stark (eds.). New York: North Holland, 21-79.

Case, A. 2004. "Does money protect health status? Evidence from South African pensions." Chapter 7 in Perspectives on the Economics of Aging, D. Wise (ed.), University of Chicago Press, 287-305.

Case, A. and A. Deaton. 2006. "Health and wellbeing in Udaipur and South Africa." Forthcoming in Developments in the Economics of Aging, D. Wise (ed) University of Chicago Press for the NBER.

Food and Agriculture Organization of the United Nations. 2006. "The developing world's new burden: obesity," accessed on line July 27, 2006 at http://www.fao.org/FOCUS/E/obesity/obes1.htm .

Furnham, A. and P. Baguma. 1994. "Cross-cultural differences in the evaluation of male and female body shapes." International Journal of Eating Disorders 15(1):81-9.

Hoddinott, J. and L. Haddad. 1995. "Does female income share influence household expenditures? Evidence from Cote D'Ivoire." Oxford Bulletin of Economics and Statistics 57: 77-96.

Holdsworth, M., A. Gartner, E. Landais, B. Maire and F. Delpeuch. 2004. "Perceptions of healthy and desirable body size in urban Senegalese women." International Journal of Obesity 28: 1561-8.

Kahn, K., S.M. Tollman, M. Garenne, and J.S.S. Gear. 1999. "Who dies from what? Determining cause of death in South Africa's rural northeast." Tropical Medicine and International Health 4(6): 433-41.

Leibbrandt, M., L. Poswell, P. Naidoo, M. Welch, and I. Woolard. 2005. "Measuring recent changes in South African inequality and poverty using 1996 and 2001 Census data." Working Paper 9629, Development Policy Research Unit, University of Cape Town.

Martorell, R., L. Kettel Khan, M. L. Hughes, and L. M. Grummer-Strawn. 2000. "Obesity in women from developing countries." European Journal of Clinical Nutrition 54(3): 247-52.

Onyike, Chiadi U., Rosa M. Crum, Hochange B. Lee, Constantine G. Lyketsos, and William W. Eaton. 2003. "Is obesity associated with major depression? Results from the Third National Health and Nutrition Examination Survey." American Journal of Epidemiology 158(12): 1139-47. 
Popkin, B.M. 1994. "The nutrition transition in low income countries: An emerging crisis." Nutrition Reviews 52(9): 285-98.

Popkin B.M. and C. M. Doak. 1998. "The obesity epidemic is a worldwide phenomenon.” Nutrition Reviews 56: 106-14.

Puoane, T., K. Steyn, D. Bradshaw, R. Laubscher, J. Fourie, V. Lambert, and N. Mbananga. 2002. "Obesity in South Africa: The South African Demographic and Health Survey." Obesity Research 10: 1038-48.

Varma, Amit, Jing He, Lisa Weissfeld, and Sherin U. Devaskar, 2003. "Postnatal intracerebroventricular exposure to neuropeptide Y causes weight loss in female adult rats.” Am J Physiol Regulatory Integrative Comp Physiol, 284:1560-1566.

World Health Organization. 2000. Obesity: Preventing and managing the global epidemic. Report of a WHO consultation. Technical Report Series 894: 1-253.

Ziebland, S., J. Robertson, J. Jay and A. Neil. 2002. "Body image and weight change in middle age: A qualitative study." International Journal of Obesity 26: 1083-91. 
Figure 1. Body mass indices for men and women, Khayelitsha Survey 2004-05

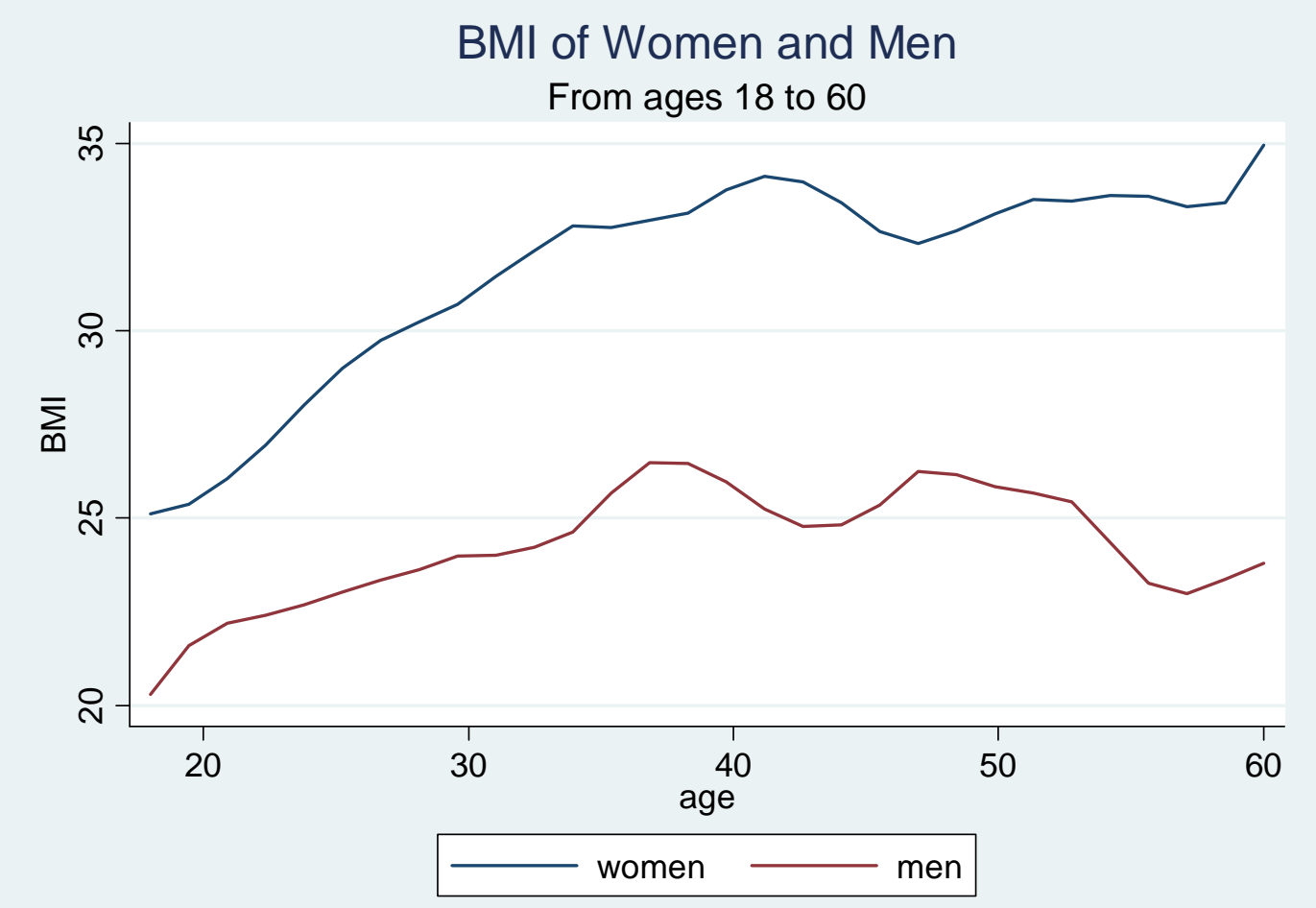


Figure 2. Body images by sex (Source: Ziebland et al. 2002)
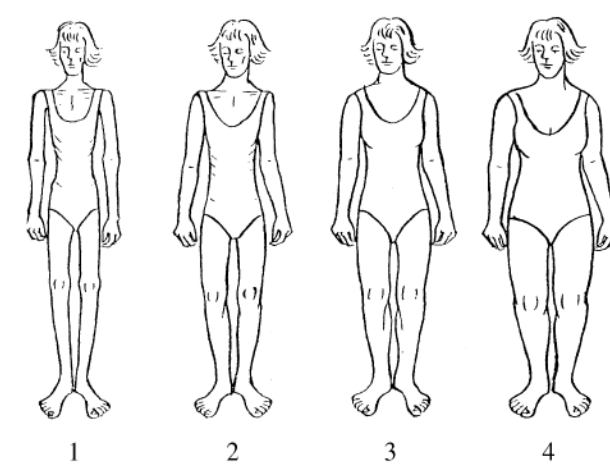

Figure 1 The illustrations of body shapes used for women.

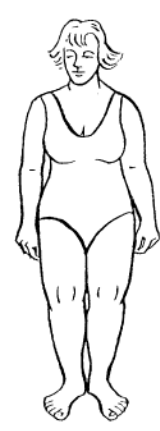

5

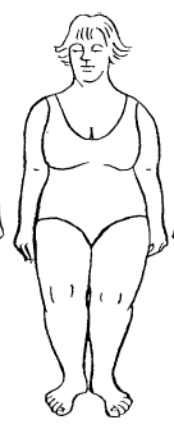

6

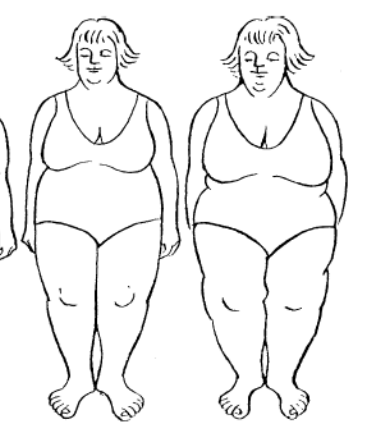

8

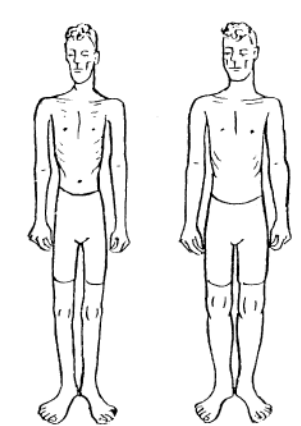

1

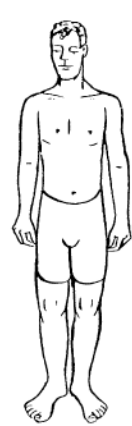

3

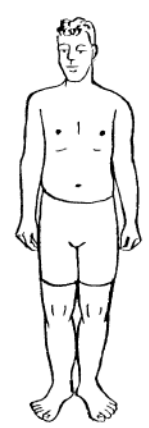

4

Figure 2 The illustrations of body shapes used for men.

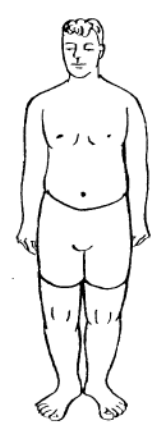

5

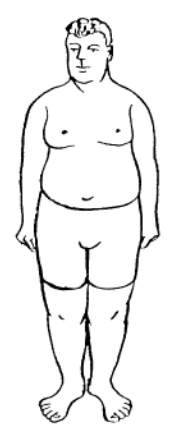

6

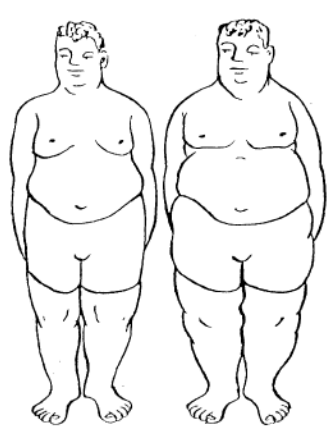

8

International Journal of Obesity 
Figure 3. Perceived body shapes and desired body shapes for women

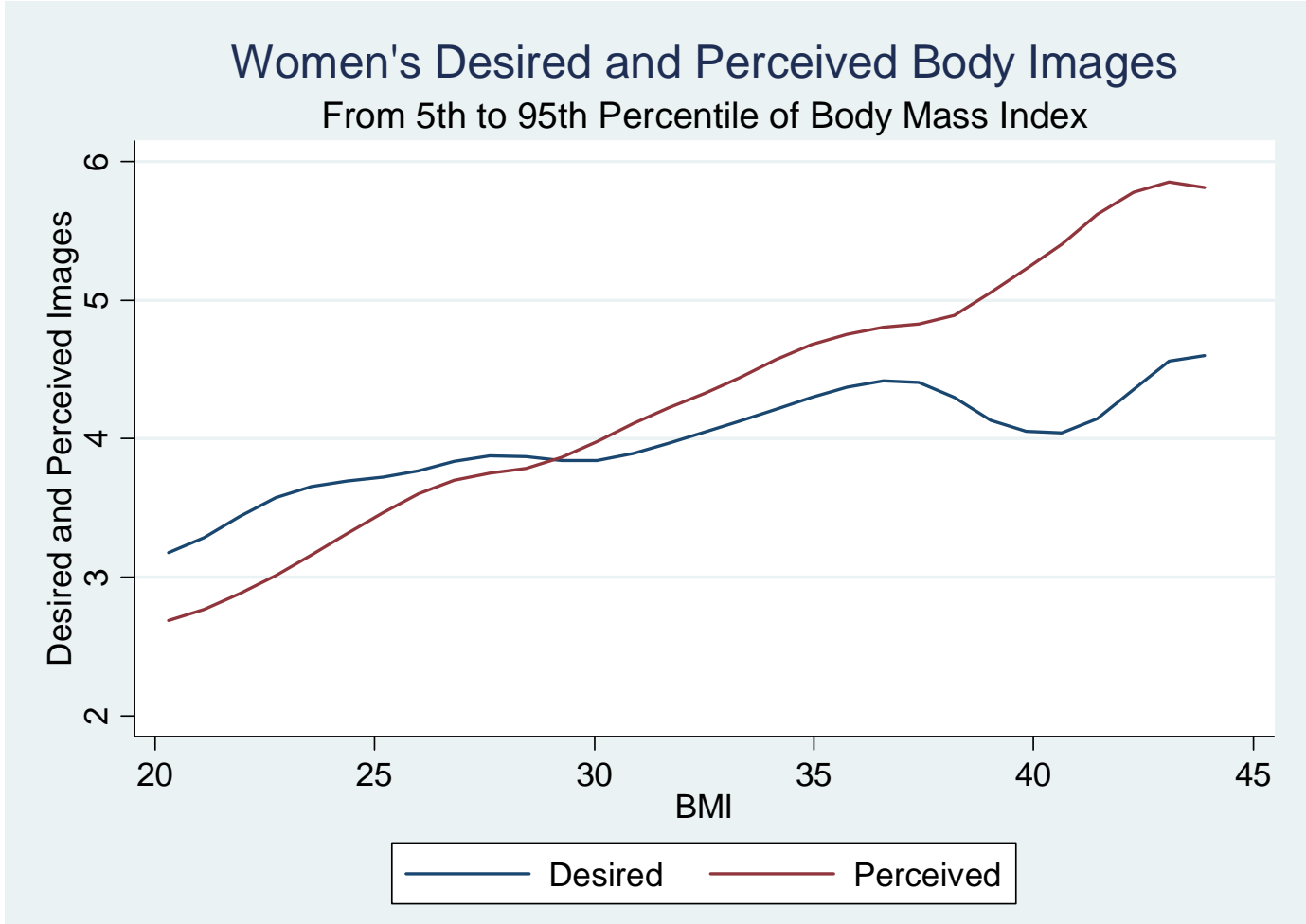




\begin{tabular}{|c|c|c|c|}
\hline & $\begin{array}{c}\text { Men } \\
(n=426)\end{array}$ & $\begin{array}{l}\text { Women } \\
(\mathrm{n}=549)\end{array}$ & $\begin{array}{l}p \text {-value of } \\
\text { difference }\end{array}$ \\
\hline Age & 35.49 & 36.14 & 0.454 \\
\hline \multicolumn{4}{|l|}{ Body mass index (BMI) } \\
\hline Indicator: underweight $(\mathrm{BMI}<18.5)$ & 0.052 & 0.011 & 0.000 \\
\hline Indicator: normal $(18.5 \leq \mathrm{BMI}<25)$ & 0.643 & 0.219 & 0.000 \\
\hline Indicator: overweight $(25 \leq \mathrm{BMI}<30)$ & 0.204 & 0.268 & 0.021 \\
\hline Indicator: obese $(\mathrm{BMI} \geq 30)$ & 0.101 & 0.503 & 0.000 \\
\hline \multicolumn{4}{|l|}{ Proximate causes of obesity } \\
\hline \multicolumn{4}{|l|}{ Food consumption } \\
\hline Indicator: large breakfast & 0.209 & 0.075 & 0.000 \\
\hline Indicator: large lunch & 0.194 & 0.059 & 0.000 \\
\hline Indicator: large dinner & 0.292 & 0.142 & 0.000 \\
\hline Number of large meals per day & 0.698 & 0.272 & 0.000 \\
\hline Spoons of sugar per day & 4.337 & 6.579 & 0.000 \\
\hline Indicator: drinks soda & 0.308 & 0.255 & 0.070 \\
\hline \multicolumn{4}{|l|}{ Physical exertion } \\
\hline Any exercise & 0.333 & 0.093 & 0.000 \\
\hline Any sports & 0.188 & 0.035 & 0.000 \\
\hline \multicolumn{4}{|l|}{ Underlying causes of obesity } \\
\hline \multicolumn{4}{|l|}{ Childhood conditions } \\
\hline Indicator: Went to school hungry & 0.380 & 0.368 & 0.687 \\
\hline Indicator: Went to bed hungry & 0.378 & 0.338 & 0.198 \\
\hline Indicator: Ate at other people's homes & 0.266 & 0.283 & 0.557 \\
\hline Child poverty index & 1.021 & 0.982 & 0.630 \\
\hline \multicolumn{4}{|l|}{ Adult socioeconomic status } \\
\hline Years of completed education & 6.26 & 6.77 & 0.010 \\
\hline Log(expenditure per member) & 5.490 & 5.361 & 0.003 \\
\hline Log(income per member) & 5.858 & 5.588 & 0.000 \\
\hline \multicolumn{4}{|l|}{ Depression index } \\
\hline 'Some' or 'Most of the time' & 1.977 & 2.756 & 0.000 \\
\hline \multicolumn{4}{|l|}{ Body shapes } \\
\hline Perceived current body shape & 3.314 & 4.106 & 0.000 \\
\hline Ideal body shape & 3.693 & 3.949 & 0.000 \\
\hline
\end{tabular}




\section{Table 2. Proximate Determinants of Obesity}

\begin{tabular}{lccc}
\multicolumn{2}{c}{ Dependent variable $=1$ if BMI $>30,=0$ otherwise } \\
Control variables: & Women & Men \\
\cline { 2 - 2 } Number of large meals per day & 0.039 & & -0.008 \\
& $(0.034)$ & & $(0.018)$ \\
Indicator: Drinks soda & 0.109 & & 0.068 \\
& $(0.044)$ & & $(0.036)$ \\
Sugar index & 0.051 & & -0.013 \\
& $(0.022)$ & & $(0.021)$ \\
Reports exercise & -0.008 & & -0.005 \\
& $(0.065)$ & & $(0.044)$ \\
Reports sports & -0.017 & & 0.010 \\
& $(0.108)$ & $(0.044)$ \\
$F$-test: calorie intake variables & 4.27 & 1.22 \\
( $p$-value) & $(0.006)$ & $(0.303)$ \\
$F$-test: calorie expenditure variables & 0.03 & 0.02 \\
$(p$-value) & $(0.970)$ & $(0.976)$ \\
Number of observations & 536 & 404 \\
\hline \hline
\end{tabular}

OLS regression coefficients reported, with standard errors in parentheses. Standard errors allow for correlation in the unobservables between individuals in the same household. Also included in all regressions are controls for age, age squared, an indicator for the survey year, and a constant term. 


\begin{tabular}{|c|c|c|}
\hline Obesity rate, women & 0.503 & \\
\hline Obesity rate, men & 0.101 & \\
\hline Difference (women - men) & 0.402 & \\
\hline Severity effect $\quad \sum_{i}\left(\beta_{i}^{F}-\beta_{i}^{M}\right) \overline{x_{i}}$ & 0.089 & \\
\hline Prevalence effect $\quad \sum_{i}\left(\overline{x_{i}^{F}}-\overline{x_{i}^{M}}\right) \overline{\beta_{i}}$ & -0.004 & \\
\hline Fraction explained & 0.211 & \\
\hline Decomposition by variable: & $\begin{array}{l}\text { Severity Effect } \\
\left(\beta_{i}^{F}-\beta_{i}^{M}\right) \overline{x_{i}}\end{array}$ & $\begin{array}{l}\text { Prevalence Effect } \\
\qquad\left(\overline{x_{i}^{F}}-\overline{x_{i}^{M}}\right) \overline{\beta_{i}}\end{array}$ \\
\hline Number of large meals per day & 0.021 & -0.007 \\
\hline Indicator: Drinks soda & 0.011 & -0.005 \\
\hline Sugar index & 0.060 & 0.005 \\
\hline Reports exercise & -0.001 & 0.002 \\
\hline Reports sports & -0.003 & 0.001 \\
\hline All & 0.089 & -0.004 \\
\hline
\end{tabular}

Decomposition is based on OLS regression coefficients reported in columns 1 and 2 of Table 2. 


\section{Table 4. Underlying Determinants of Obesity}

Dependent variable $=1$ if $\mathrm{BMI}>30,=0$ otherwise

\begin{tabular}{|c|c|c|c|c|c|c|}
\hline \multirow[b]{3}{*}{ Control variables: } & \multicolumn{3}{|c|}{ Women } & \multicolumn{3}{|c|}{ Men } \\
\hline & (1) & (2) & (3) & (4) & (5) & (6) \\
\hline & & & & & & \\
\hline Childhood hunger index & $\begin{array}{c}0.048 \\
(0.016)\end{array}$ & $\begin{array}{c}0.044 \\
(0.101)\end{array}$ & $\begin{array}{c}0.008 \\
(0.138)\end{array}$ & $\begin{array}{l}-0.005 \\
(0.012)\end{array}$ & $\begin{array}{c}0.004 \\
(0.061)\end{array}$ & $\begin{array}{c}0.020 \\
(0.080)\end{array}$ \\
\hline $\begin{array}{l}\text { Childhood hunger index } \times \\
\log (\text { income/member })\end{array}$ & -- & $\begin{array}{c}0.001 \\
(0.018)\end{array}$ & -- & -- & $\begin{array}{l}-0.001 \\
(0.010)\end{array}$ & -- \\
\hline $\begin{array}{l}\text { Childhood hunger index } \times \\
\log (\text { expenditure/member })\end{array}$ & -- & -- & $\begin{array}{c}0.008 \\
(0.025)\end{array}$ & -- & -- & $\begin{array}{l}-0.005 \\
(0.014)\end{array}$ \\
\hline $\begin{array}{l}F \text {-test: childhood hunger } \\
\text { variables ( } p \text {-value) }\end{array}$ & -- & $\begin{array}{c}4.67 \\
(0.010)\end{array}$ & $\begin{array}{c}5.19 \\
(0.006)\end{array}$ & -- & $\begin{array}{c}0.10 \\
(0.909)\end{array}$ & $\begin{array}{c}0.19 \\
(0.829)\end{array}$ \\
\hline Log (income/member) & $\begin{array}{c}0.041 \\
(0.020)\end{array}$ & $\begin{array}{c}0.041 \\
(0.028)\end{array}$ & -- & $\begin{array}{l}-0.011 \\
(0.014)\end{array}$ & $\begin{array}{l}-0.010 \\
(0.019)\end{array}$ & -- \\
\hline Log (expend/member) & -- & -- & $\begin{array}{c}0.032 \\
(0.044)\end{array}$ & -- & -- & $\begin{array}{l}-0.020 \\
(0.025)\end{array}$ \\
\hline Education & $\begin{array}{c}0.019 \\
(0.009)\end{array}$ & $\begin{array}{c}0.019 \\
(0.009)\end{array}$ & $\begin{array}{c}0.019 \\
(0.009)\end{array}$ & $\begin{array}{c}0.009 \\
(0.005)\end{array}$ & $\begin{array}{c}0.009 \\
(0.005)\end{array}$ & $\begin{array}{c}0.008 \\
(0.005)\end{array}$ \\
\hline Depression index & $\begin{array}{l}-0.003 \\
(0.008)\end{array}$ & $\begin{array}{l}-0.003 \\
(0.008)\end{array}$ & $\begin{array}{l}-0.004 \\
(0.008)\end{array}$ & $\begin{array}{l}-0.007 \\
(0.006)\end{array}$ & $\begin{array}{l}-0.007 \\
(0.006)\end{array}$ & $\begin{array}{l}-0.007 \\
(0.006)\end{array}$ \\
\hline $\mathrm{N}$ observations & 528 & 528 & 540 & 402 & 402 & 417 \\
\hline
\end{tabular}

OLS regression coefficients reported, with standard errors in parentheses. Standard errors allow for correlation in the unobservables between individuals in the same household. Also included in all regressions are controls for age, age squared, an indicator for the survey year, and a constant term. 
Table 5. Decomposition of the Underlying Determinants of Obesity

\begin{tabular}{|c|c|c|c|c|}
\hline & \multicolumn{2}{|c|}{$\begin{array}{c}\text { Using } \\
\text { log(income per } \\
\text { member) }\end{array}$} & \multicolumn{2}{|c|}{$\begin{array}{c}\text { Using } \\
\log (\text { expenditure per } \\
\text { member })\end{array}$} \\
\hline Obesity rate, women & 0.503 & & 0.503 & \\
\hline Obesity rate, men & 0.101 & & 0.101 & \\
\hline Difference (women - men) & 0.402 & & 0.402 & \\
\hline Severity effect & 0.414 & & 0.413 & \\
\hline Prevalence effect & -0.001 & & 0.001 & \\
\hline Fraction explained & 1.027 & & 1.030 & \\
\hline Decomposition by variable: & $\begin{array}{l}\text { Severity } \\
\text { Effect }\end{array}$ & $\begin{array}{l}\text { Prevalence } \\
\text { Effect }\end{array}$ & $\begin{array}{l}\text { Severity } \\
\text { Effect }\end{array}$ & $\begin{array}{l}\text { Prevalence } \\
\text { Effect }\end{array}$ \\
\hline Childhood hunger index & 0.041 & -0.001 & -0.012 & -0.001 \\
\hline $\begin{array}{l}\text { Childhood hunger } \times \log (\mathrm{SES} \\
\text { measure })\end{array}$ & 0.012 & 0.000 & 0.066 & -0.001 \\
\hline $\log ($ SES measure $)$ & 0.289 & -0.004 & 0.278 & -0.001 \\
\hline Education & 0.063 & 0.007 & 0.073 & 0.007 \\
\hline Depression index & 0.009 & -0.004 & 0.008 & -0.004 \\
\hline All & 0.414 & -0.001 & 0.413 & 0.001 \\
\hline
\end{tabular}

The decomposition in columns 1 and 2 is based on OLS regression coefficients reported in columns 2 and 5 of Table 4, which uses $\log$ (income per member) as an SES control, and the decomposition in columns 3 and 4 is based on regression coefficients reported in columns 3 and 6 of Table 4, which uses $\log$ (expenditure per member) as an SES control. 


\begin{tabular}{|c|c|c|c|c|}
\hline & \multicolumn{2}{|c|}{$\begin{array}{l}\text { Dependent Variable: } \\
\text { Childhood hunger } \\
\text { index }\end{array}$} & \multicolumn{2}{|c|}{$\begin{array}{c}\text { Dependent } \\
\text { Variable: Obesity in } \\
\text { adulthood }\end{array}$} \\
\hline & Women & Men & Women & Men \\
\hline Childhood hunger index & -- & -- & $\begin{array}{c}0.053 \\
(0.022)\end{array}$ & $\begin{array}{l}-0.008 \\
(0.016)\end{array}$ \\
\hline \multicolumn{5}{|l|}{ Childhood family finances were: } \\
\hline $\begin{array}{l}\text { "very comfortable" or } \\
\text { "comfortable" }\end{array}$ & $\begin{array}{l}-2.201 \\
(0.162)\end{array}$ & $\begin{array}{l}-2.164 \\
(0.183)\end{array}$ & $\begin{array}{c}0.076 \\
(0.110)\end{array}$ & $\begin{array}{l}-0.067 \\
(0.077)\end{array}$ \\
\hline "just getting by" & $\begin{array}{l}-1.799 \\
(0.166)\end{array}$ & $\begin{array}{l}-1.749 \\
(0.177)\end{array}$ & $\begin{array}{l}-0.004 \\
(0.091)\end{array}$ & $\begin{array}{c}0.006 \\
(0.069)\end{array}$ \\
\hline "poor" & $\begin{array}{l}-0.495 \\
(0.186)\end{array}$ & $\begin{array}{l}-0.597 \\
(0.207)\end{array}$ & $\begin{array}{c}0.017 \\
(0.083)\end{array}$ & $\begin{array}{l}-0.024 \\
(0.060)\end{array}$ \\
\hline $\begin{array}{l}\text { Father did not have a "regular pay } \\
\text { job" }\end{array}$ & $\begin{array}{c}0.177 \\
(0.117)\end{array}$ & $\begin{array}{c}0.224 \\
(0.123)\end{array}$ & $\begin{array}{l}-0.002 \\
(0.046)\end{array}$ & $\begin{array}{l}-0.032 \\
(0.034)\end{array}$ \\
\hline $\begin{array}{l}F \text {-test: joint significance of family } \\
\text { finance indicator variables }\end{array}$ & 101.25 & 60.83 & 0.47 & 1.08 \\
\hline Number of observations & 502 & 399 & 502 & 399 \\
\hline
\end{tabular}

Notes: Also included are age, age squared, an indicator for survey year, and a constant term. All regressions allow for correlation in the unobservables for observations from the same household. 


\section{Table 7. Own Income, Household Income and Obesity}

Dependent variable: Obesity in adulthood

\begin{tabular}{|c|c|c|c|c|c|}
\hline \multirow[b]{3}{*}{$\begin{array}{l}\text { Total household income per } \\
\text { month (R1000) }\end{array}$} & \multicolumn{3}{|c|}{ Women } & \multicolumn{2}{|c|}{ Men } \\
\hline & (1) & (2) & (3) & (4) & (5) \\
\hline & $\begin{array}{c}0.033 \\
(0.014)\end{array}$ & $\begin{array}{c}0.019 \\
(0.016)\end{array}$ & $\begin{array}{c}0.021 \\
(0.016)\end{array}$ & $\begin{array}{c}0.005 \\
(0.012)\end{array}$ & $\begin{array}{l}-0.001 \\
(0.013)\end{array}$ \\
\hline $\begin{array}{l}\text { Own earnings from work per } \\
\text { month (R1000) }\end{array}$ & -- & $\begin{array}{c}0.062 \\
(0.027)\end{array}$ & $\begin{array}{c}0.052 \\
(0.027)\end{array}$ & -- & $\begin{array}{r}0.015 \\
(0.024)\end{array}$ \\
\hline $\begin{array}{l}\text { Monthly child support grant } \\
\text { receipt (R1000) }\end{array}$ & -- & $\begin{array}{c}0.337 \\
(0.169)\end{array}$ & $\begin{array}{c}0.268 \\
(0.172)\end{array}$ & -- & -- \\
\hline $\begin{array}{l}\text { Indicator: respondent has } \\
\text { 'most say' on food spending }\end{array}$ & -- & -- & $\begin{array}{c}0.102 \\
(0.062)\end{array}$ & -- & $\begin{array}{r}0.022 \\
(0.045)\end{array}$ \\
\hline $\begin{array}{l}F \text {-test: joint significance of } \\
\text { own-income and 'most say' } \\
\text { variables ( } p \text {-value) }\end{array}$ & & & $\begin{array}{c}2.94 \\
(0.033)\end{array}$ & & $\begin{array}{c}0.48 \\
(0.617)\end{array}$ \\
\hline Number of observations & 511 & 511 & 511 & 375 & 375 \\
\hline
\end{tabular}

Notes: Also included in all regressions are controls for age, age squared survey year, number of household members, our childhood hunger index, and a constant term. Standard errors that allow for correlation in the unobservables for observations from the same household are presented in parentheses. The sample excludes 4 outliers for whose reported total household monthly income exceeded R10,000. 


\section{Table 8. Decisions on Household Food Spending}

Dependent variable $=1$ if this adult is reported to have the "most say" on food spending

\begin{tabular}{lc}
\hline \hline Female & 0.172 \\
& $(0.053)$ \\
Total household income & -0.024 \\
$(\mathrm{R} 1000)$ & $(0.016)$ \\
Female $\times$ total household & 0.012 \\
income (R1000) & $(0.020)$ \\
Own-earnings from work & 0.055 \\
(R1000) & $(0.032)$ \\
Female $\times$ own-earnings from & 0.126 \\
work (R1000) & $(0.045)$ \\
Female $\times$ child support grant & 0.822 \\
receipt $(\mathrm{R} 1000)$ & $(0.157)$ \\
Number of observations & 649 \\
\hline \hline
\end{tabular}

Notes: Also included are controls for household size, respondents' education, age, age squared, an indicator for survey year, and a constant term. The sample is restricted to adults living in households that contain both adult men and women. The sample excludes 4 outliers reporting total household monthly income above R10,0000. Standard errors that allow for correlation in the unobservables for observations from the same household are presented in parentheses. 